\title{
Turismo oscuro: las visitas a catacumbas y cementerios como forma de sentir la muerte en vida
}

\author{
Carmen Haro Cáceres y Paula Resta Serrano | Historiadoras del arte \\ URL de la contribución <www.iaph.es/revistaph/index.php/revistaph/article/view/5062>
}

El turismo oscuro fue un término acuñado por dos profesores británicos, John Lennon y Malcolm Folney, en el año 1996. Estos mismos aseguraban que no era una moda en auge, sino que existía desde tiempo atrás, cuando los peregrinos viajaban para visitar tumbas o lugares santos. Este turismo ha ido evolucionando hasta nuestros días, consiguiendo crear verdaderos espacios de visitas, e incluso recreo. Ejemplos de ello son Auschwitz y otros campos de exterminio y concentración; los campo de la muerte en Camboya; la plaza Dealey en Dallas (donde fue asesinado John F. Kenndy); el edificio de Dakota en Nueva York, lugar del asesinato de John Lennon; o la famosa zona cero de la misma ciudad, donde se produjo el atentado de las Torres Gemelas (Turismo oscuro 2018).

Remontándonos al pasado, nos encontramos con otras prácticas muy habituales que forman parte de este turismo oscuro. Se trata de las visitas a espacios de muerte, lugares como cementerios, tumbas, catacumbas, osarios, etc. En lo que respecta a los osarios o catacumbas, prestaremos especial atención a dos casos muy destacados: las catacumbas de París y el cementerio delle Fontanelle en Nápoles.

El primer caso es, sin lugar a duda, uno de los cementerios más visitados en Europa, recibiendo al año unos 250.000 visitantes. Consiste en una red de túneles y cuartos subterráneos que datan de época romana y que fueron convertidos en un cementerio común a finales del siglo XVIII. Actualmente es un osario que alberga más de seis millones de huesos, siendo uno de los mayores de Europa. La entrada a este espacio se encuentra en la plaza Denfert-Rochereau. Si queremos llegar a la galería, antes tenemos que adentrarnos unos 20 metros bajo tierra, encontrándonos nada más llegar una serie de exposiciones temporales. Aquí comienza el recorrido de, aproximadamente, unos dos kilómetros repletos de galerías. La visita está enmarcada en el lema "Arrête! C'est ici l'empire de la mort" en francés, o traducido al español, "iDetente!, este es el imperio de la muerte" frase que aparece grabada en un dintel en la entrada a las catacumbas. ¿Puede ser más terrorífico este inicio de visita? (Catacumbas s.f.).

El segundo caso del que hablaremos es otro osario, unas catacumbas situadas en la ciudad metropolitana de Nápoles, al sur de Italia. El cementerio delle Fontanelle, también conocido como el cementerio de las Pilas, se ubica en el barrio de Sanità, data del siglo XVI y su nombre se debe a la presencia de fuentes en ese espacio. Es conocido especialmente por su historia, albergando los huesos de cientos de napolitanos. Se contabilizan alrededor de unos 40.000 restos que pertenecen, principalmente, a víctimas de la gran plaga de 1656 y de la epidemia de cólera de 1836. En este osario, además, se practica el famoso ritual de las almas pazzentelle. o lo que es lo mismo, la adopción de un cráneo (un alma abandonada) a cambio de protección, coincidiendo con las tradiciones religiosas por las que se caracterizan los napolitanos (Fontanelle s.f.).

Otro de los ejemplos que forman parte de esta práctica de turismo oscuro es, como hemos matizado antes, la visita a cementerios. Hasta hace unos años estos eran ese lugar al que acudimos cuando un ser querido fallece. Pero hoy en día, además, algunos cementerios son lugares de atracción turística.

Los dos tipos de cementerios en los que se pueden clasificar los visitados por la gente son: 
1. Cementerios donde están enterrados personajes famosos: Visitar tumbas de famosos, es algo muy importante y simbólico para aquellos que admiraban a la persona en cuestión en vida. Muchas personas se acercan a diario a las tumbas de famosos, convirtiéndolas en auténticos lugares de peregrinación. Es cierto que hay varios cementerios donde esto sucede, pero uno que sobresale es el cementerio de Père-Lachaise en París. Decenas y decenas de personalidades de todas las épocas y ámbitos reposan aquí y reciben miles de visitas de sus admiradores, quienes les rinden homenajes. Algunas de estas personalidades son: la cantante Édith Piaf, el escritor Oscar Wilde, el pintor Eugène Delacroix, el cantante Jim Morrison e incluso el dictador Rafael Leónidas Trujillo (Mendoza 2015).

En España tenemos un caso parecido, el del cementerio de la Almudena, en Madrid, que si bien es cierto que no es tan concurrido como el parisino tiene algunas tumbas de personalidades importantes, siendo quizás la más visitada el monumento erigido en honor a las Trece rosas. Aunque también destacan tumbas como la del médico Santiago Ramón y Cajal o la de la bailaora y cantante Lola Flores.

2. Los cementerios como obra de arte: Aparentemente este título puede resultar bastante desconcertante, pues resulta chocante imaginar que en un cementerio se encuentre una obra de arte, pero lo cierto es que las esculturas que presiden algunas de las tumbas de muchos camposantos son de una belleza y calidad que nada tienen que envidiar a las esculturas presentes en los grandes museos. Un cementerio que entraría en esta categoría es el cementerio monumental de Staglieno, en Génova, Italia. Aquí las tumbas son impresionantes a la par que sobrecogedoras. En las tumbas están representados en ocasiones los difuntos acompañados de un ángel, o la figura religiosa sola, e incluso aparecen alegorías. También es frecuente encontrar en este cementerio continuas alusiones al campo marítimo, puesto que en la zona esta actividad es muy común (Cementerio Monumental s.f.). Otra cosa que le da a este cementerio un valor añadido es que el tiempo y los factores meteorológicos han hecho mella en las tumbas, dejando a algunas esculturas con un aspecto particular y en ocasiones algo tétrico.

En España, aún a riesgo de parecer repetitivas, podemos volver a citar el ejemplo de la Almudena, en Madrid.

En definitiva, todos los ejemplos que hemos expuesto en este artículo hablan de una necesidad. De aquella que parte del ser humano como miembro de una comunidad en la que se deleita con el morbo, con temas tan tenebrosos como la muerte, el sufrimiento o el miedo. Este tipo de turismo, por tanto, se convierte en una forma más de hacernos partícipes de la parte triste y macabra de la historia de la humanidad.

\section{BIBLIOGRAFÍA}

- Cementerio Monumental de Staglieno, arte escultórico de Génova entre 1850 y 1950 [Guía del cementerio de Staglieno] (s.f.). Genova more than this. Disponible en: https://www.visitgenoa.it/sites/default/files/Cementerio\%20 Monumental\%20de\%20Staglieno_0.pdf [Consulta: 13/11/2021]

- El cementerio de Fontanelle en Nápoles (s.f.). En: Napolike Turismo. Disponible en: https://es.napolike.com/turismo/place/ cimitero-delle-fontanelle-napoli/ [Consulta: 05/11/2021]

- Inmersión en medio de las Catacumbas de París (s.f.). París. Web Oficial de la Oficina de Turismo y Congresos de París. Disponible en: https://es.parisinfo.com/que-visitar-enparis/info/guias/inmersion-en-medio-de-las-catacumbas-deparis [Consulta: 05/11/2021]

- Mendoza, E.S.G (2015) El Cementerio Pere-Lachaise: un patrimonio cultural mundial. Anales de la Academia de Geografía e Historia de Guatemala, n. ${ }^{\circ}$ 90, pp. 267 y ss.

- Qué es el turismo oscuro, la tendencia en auge a visitar lugares marcados por la tragedia (2018). BBC News, 30 de noviembre de 2018. Disponible en: https://www.bbc.com/ mundo/noticias-46395319 [Consulta: 05/11/2021] 